\title{
ENHANCING THE USDA FAS CROP FORECASTING SYSTEM USING SMAP L3 SOIL MOISTURE OBSERVATIONS
}

\author{
Iliana E. Mladenova ${ }^{1,2 *}$, John D. Bolten ${ }^{1}$, Wade Crow ${ }^{3}$, Curt Reynolds ${ }^{4}$ \\ ${ }^{1}$ National Aeronautics and Space Administration, Goddard Space Flight Center, Greenbelt, MD; \\ ${ }^{2}$ Univeristy of Maryland, College Park, MD; ${ }^{3}$ U.S. Department of Agriculture, Hydrology and Remote \\ Sensing Lab, Beltsville, MD; ${ }^{4}$ U.S. Department of Agriculture, Foreign Agricultural Services, \\ Washington, DC; *corresponding author: Iliana.E.Mladenova@nasa.gov
}

\begin{abstract}
One of the U.S. Department of Agriculture-Foreign Agricultural Services (USDA-FAS) mission objectives is to provide current information on global crop supply and demand estimates. Crop growth and development is especially susceptible to the amount of water present in the root-zone portion of the soil profile. Therefore, accurate knowledge of the root-zone soil moisture (RZSM) is an essential for USDA-FAS global crop assessments. This paper focusses on the possibility of enhancing the USDAFAS's RZSM estimates through the integration of passivebased soil moisture observations derived from the Soil Moisture Active Passive (SMAP) mission into the USDAFAS Palmer model. Lag-correlation analysis, which explores the agreement between changes in RZSM and crop status indicated that the satellite-based observations can enhance the model-only estimates.
\end{abstract}

Index Terms - SMAP, root-zone soil moisture, agriculture.

\section{INTRODUCTION}

Foreign Agricultural Services (FAS) is a subdivision of U.S. Department of Agriculture (USDA) whose main mission objective is to enhance global trade opportunities and global food security through the establishment of international trade standards and rules, market development and export assistance as wells as agricultural improvement and trade capacity building (https://www.fas.usda.gov/about-fas). USDA-FAS programs heavily rely on extensive objective intelligence data analysis that provide information on current market conditions, expected crop production forecasts, import and export opportunities, etc. The agency's forecasting activities related to agricultural productivity and commodities markets are based on convergence of evidence methodology that takes into consideration a large variety of agro-meteorological parameters. Crop growth and development, and the resulting end-of-season production are primarily a function of heat accumulation and plant available water, where the latter is strongly dependent on the amount of water present on the root-zone. Therefore, a major concern for the USDA-FAS crop analysts is the timely detection of agricultural drought and monitoring root-zone soil moisture (RZSM) changes that can impact the agricultural productivity. The previous soil moisture model employed by the FAS was driven exclusively by satellitebased precipitation estimates, and was prone to errors and uncertainty due to the inconsistent nature of those datasets. Our main goal is to enhance the USDA-FAS global crop assessment decision support system via improving their RZSM information through the assimilation of passive-based soil moisture observations derived from the Soil Moisture Active Passive (SMAP) mission.

\section{METHODOLOGY AND SYSYTEM OVERVIEW}

The current baseline RZSM estimates unitized by USDAFAS are developed using the modified two-layer Palmer model [1]. The Palmer model is a water-balance-based hydrologic model that is driven by daily estimates of minimum and maximum temperature, and daily precipitation observations. These meteorological data are based on ground meteorological station measurements from the World Meteorological Organization (WMO), and gridded weather data from the former U.S. Air Force Weather Agency (AFWA), currently called U.S. Air Force $557^{\text {th }}$ Weather Wing. Generally, the model accuracy is determined by the quality of the precipitation forcing data. Past research have demonstrated that data assimilation of satellite-based earth observations into the model can correct for precipitationrelated inaccuracies and improve the model's soil moisture information [2, 3, 4]. Thus, the Palmer model was enhanced by adding a data assimilation unit, which allows the integration of remotely-sensed soil moisture observations. Here we assimilate the L3 passive-only soil moisture estimates derived using brightness temperature data collected by the SMAP system. We employ a 1-D Kalman 

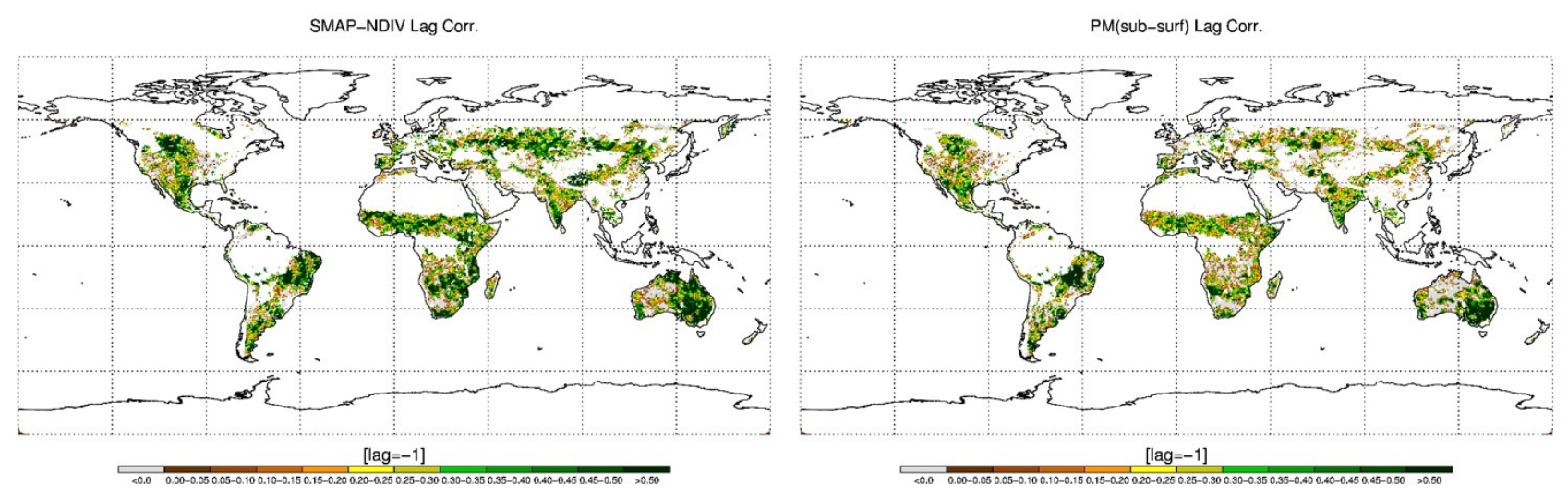

Figure 1 Default SMAP and model lag correlation results at lag $=1$ month.

Filter approach set to run with 30 ensemble members to assimilate the satellite-based data into the model.

A major part of setting up a well-functioning data assimilation system is properly parameterizing the model $(R)$ and the observation $(Q)$ error. As already described, the model accuracy is related to the uncertainty of the precipitation. Since the AFWA product incorporates the WMO ground-based data we used the density of the gauge stations to determine $Q$, where higher confidence was assign to the model the closer the model grid is to a gauge location. $R$ was parameterized as a function of the unbiased Root Mean Square Error values published by the SMAP Cal/Val team [5].

\section{DISCUSSION}

RZSM information is essential for the on-time detection of agricultural drought and the proper assessment of its impact on crop growth. Crops have numerous coping mechanisms to deal with environmental stresses including water shortage. Therefore, the change in vegetation status will not occur simultaneously with the change in root-zone soil moisture conditions. To explore this delay in agreement we examined the lag correlation between soil moisture and the Normalized Different Vegetation Index (NDVI), where NDVI was used as an indicator of vegetation health. Figure 1 shows the default SMAP-NDVI (left plot) and PM-NDVI (right plot) lag-correlation results at a lag of one month (i.e., SM precedes the change in vegetation by one month, lag = 1). As it can be seen SMAP alone shows overall higher agreement with NDVI as compared to the model alone results indicating that SMAP has the potential to enhance the root-zone soil moisture information of the Palmer model used by USDA-FAS.

\section{CONCLUSIONS}

Accurate and timely information on factors limiting crop development and production is essential for USDA-FAS since current crop production forecasting systems require adequate knowledge of the available soil water in order to properly predict the impact of the in-season weather variations on the end-of-season crop production. This study helps to determine the value of the SMAP passive-only soil moisture data for enhancing the USDA-FAS crop forecasting system.

\section{REFERENCES}

[1] W.C. Palmer, "Meteorological Drought," U.S. Weather Bureau Research Paper, 45, 1965.

[2] J. Bolten, W. Crow, X. Zhan, C. Reynolds, T. Jackson, "Assimilation of a satellite-based soil moisture product in a twolayer water balance model for a global crop production decision support system," Data Assimilation for Atmospheric, Oceanic, and Hydrologic Applications, Springer-Verlag, Berlin Heidelberg, 2009.

[3] J.D. Bolten, W.T. Crow, X. Zhan, T.J. Jacksons, C.A. Reynolds, "Evaluating the utility of remotely sensed soil moisture retrievals for operational agricultural drought monitoring," IEEE Journal of Selected Topics In Applied Earth Observations And Remote Sensing, 3(1), pp. 57-66, March 2010.

[4] J.D. Bolten, and W.T. Crow, "Improved prediction of quasiglobal vegetation using remotely-sensed surface soil moisture," Geophysical Research Letters, 39(19), 2012.

[5] T.J. Jackson, P. O'Neill, S, Chan, R. Bindlish, A. Colliander, F. Chen, S. Dunbar, J. Piepmeier, M. Cosh, T. Caldwell, J. Walker, X. Wu, A. Berg, T. Rowlandson, A. Pacheco, H. McNairn, M. Thibeault, J. Martínez-Fernández, Á. González-Zamora, E. Lopez- 
Baeza, F. UIdall, M. Seyfried, D. Bosch, P. Starks, C. Holifield, J.

Prueger, Z. Su, R. van der Velde, J. Asanuma, M. Palecki, E. Small, M. Zreda, J. Calvet, W. Crow, Y. Kerr, S. Yueh and D. Entekhabi, "Calibration and Validation for the L2/3 SM P Version 4 and L2/3_SM_P_E Version 1 Data Products," SMAP Project, JPL D-56297, Jet Propulsion Laboratory, Pasadena, CA, December 15, 2016. 